\title{
Correction to: Astrobiology 2019; 19(6):730-756
}

"A Lunar Microbial Survival (LMS) Model for Predicting the Forward Contamination of the Moon" by Andrew C. Schuerger, John E. Moores, David J. Smith, and Günther Reitz; published in Astrobiology, 2019, vol. 19 , no. 6 , pp 730-756.

\section{Introduction}

A Lunar Microbial Survival (LMS) model (Schuerger et al., 2019) was developed to estimate the persistence of spacecraft bacteria over long periods of time on the Moon. Recently, we were extending the LMS model to include predictions for microbial survival on interplanetary spacecraft (Moores and Schuerger, 2020) and detected errors in Eqs. [2.a] and [2.b] in the original LMS paper. The following text describes the errors and how the corrected equations and MatLab programs changed the results given in Table 2 and Figure 5.

[New] 3.7.1. LMS Model; Equations (2.a) and (2.b)

In the revised Section 3.7.1., paragraph-2 (italics below), the modified text has been underlined. Please note that the 'per minute' terms in Eqs. [2.a] and [2.b] that resulted in incomplete cancellations of units within the exponential terms have been deleted.

To convert the instantaneous flux into a reduction in the bioburden, the biphasic response of $\mathrm{B}$. subtilis HA101 to solar UV irradiation (Schuerger et al., 2006) was used (Fig. 4). In this formulation, the ordinate axis was converted from time to received insolation by dividing the exponent numerators by the $U V C+U V B$ flux rate reported by Schuerger et al. (2006) (i.e., $590 \mathrm{~J} \mathrm{~m} \mathrm{~m}^{-2}$ minute $\overline{-1}$ to achieve -3.374 log reductions after 1 min); however, the elapsed time below, $\Delta t$, is expressed in seconds.

$$
\begin{aligned}
& \Delta N_{U V}(t)=\frac{N_{U V}(t+\Delta t)}{N_{0}(t)}=10^{-3.374 \times S \Delta t / 590 \mathrm{Jm}^{-2}} \quad \text { new }[2 . a] \\
& \Delta N_{U V}(t)=\frac{N_{U V}(t+\Delta t)}{N_{0}(t)}=10^{-0.062 \times S \Delta t / 590 \mathrm{Jm}^{-2}} \quad n e w[2 . b]
\end{aligned}
$$

\section{Changes to the LMS.m program in Supplemental Table S5.}

With an increase by a factor of 60 in the rate of accumulation of lethal doses ( $L D \mathrm{~s})$ by UV irradiation, it was necessary to correct the implementation of Eqs. [2.a] and [2.b]. Unfortunately, this pushed total reductions beyond the 300-log limit of numerical precision in MatLab. As a result, the code needed to be altered to express the reductions in logarithmic space rather than in an absolute number (i.e., for $500 \operatorname{logs}$ of reduction, representing this in the code as " 500 " instead of " $1 E 500$ " which is $\left.1 \times 10^{\wedge} 500\right)$ ). This had the effect of changing division and multiplication operations to addition and subtraction operations throughout the code. During the course of this editing, it was also discovered that the Temperature + Vacuum plotting algorithm (Fig. 5, top panel) was saturating the display of the data at $150 \operatorname{logs}$ of reduction (i.e., any values above $150 \operatorname{logs}$ were displayed as $150 \operatorname{logs}$ ). This has been corrected in the new code and in the new Fig. 5.

\section{Results}

The revisions described above resulted in four modifications in the original paper. First, the UV fluence rates were underestimated by a factor of 60 for external surfaces, and thus, the data in Table 2 were adjusted upwards by 60x for the UVC+UVB only model on external surfaces. These changes are indicated by bold italics in a shortened version of Table 2 here. All footnotes in Table 2 remain as in the original text [except footnote ' $b$ '] and are omitted here. The revised footnote ' $b$ ' is given below with modified text in bold italics. In addition, the overall LMS model predictions in Table 2 for external surfaces were increased proportionally to reflect the higher biocidal effect of UV irradiation; but the overall LMS model did not increase by exactly 60x because the UV flux was only a portion of the overall biocidal effects of all four space factors.

Second, Figure 5 was modified to represent the 60 -fold increase in the biocidal nature of UV irradiation on external surfaces. The legend for Figure 5 was slightly modified by deleting the last sentence and changing the value $80^{\circ}$ to $89.8^{\circ}$. A new Figure 5 has been inserted into the online version of the corrected paper.

Third, within the LMS paper, numerical text that refers to the biocidal nature of the overall LMS and UV-only models was corrected by using the new values given in Table 2 below. The primary locations for the updated text are in the Results and Discussion sections.

And fourth, the MatLab code for the LMS model required slight adjustments to accommodate the new Eqs. [2.a] and [2.b]. All program changes in Supplemental Table 5 are indicated in yellow highlights around the revised code.

Note: The changes and updates on this article have been made online as of October 1, 2020. 
Table 2. Lethal dose $(L D)$ rates and LMS predictions for individual and combined biocidal factors on the surface of the Moon using Bacillus subtilis spores as the modeled organism.

\begin{tabular}{|c|c|c|c|c|c|c|c|}
\hline \multirow[t]{2}{*}{$\begin{array}{c}\text { Environmental } \\
\text { parameter }^{\text {a }}\end{array}$} & \multirow{2}{*}{$\begin{array}{c}\text { Moon } \\
\text { surface } \\
\text { conditions }\end{array}$} & \multirow{2}{*}{$\begin{array}{c}L D \text { values per } \\
\text { biocidal } \\
\text { factor } \\
\text { (time scales) }^{c}\end{array}$} & \multirow{2}{*}{$\begin{array}{c}\text { LMS } \\
\text { model } \\
\text { latitudes }\end{array}$} & \multicolumn{3}{|c|}{$\begin{array}{c}\log _{10} \text { reductions in bioburden } \\
\text { per lunation predicted by LMS model }\end{array}$} & \multirow{2}{*}{$\begin{array}{c}\text { References } \\
\text { for } \\
L D \text { values in } \\
\text { column } 3\end{array}$} \\
\hline & & & & $\begin{array}{l}\text { External } \\
\text { surfaces }\end{array}$ & $\begin{array}{l}\text { Shallow } \\
\text { internal } \\
\text { surfaces } \\
\end{array}$ & $\begin{array}{c}\text { Deep } \\
\text { internal } \\
\text { surfaces } \\
\end{array}$ & \\
\hline \multirow{3}{*}{$\begin{array}{c}\text { Overall LMS } \\
\text { model }\end{array}$} & & & $0^{\circ}$ & -2479 & -188 & -0.02 & \\
\hline & & & $\pm 30^{\circ}$ & -2101 & -116 & -0.02 & \\
\hline & & & $\pm 60^{\circ}$ & -1163 & -16 & -0.02 & \\
\hline \multicolumn{8}{|l|}{$\begin{array}{c}\text { Individual } \\
\text { factors } \\
\end{array}$} \\
\hline \multirow{3}{*}{$\begin{array}{c}\text { UVC + UVB flux } \\
\text { on horizontal } \\
\text { surfaces }\end{array}$} & \multirow{3}{*}{$\begin{array}{c}26.8 \mathrm{~W} \mathrm{~m}^{-2} \\
(96.8 \\
\left.\mathrm{kJ} / \mathrm{m}^{2} / \mathrm{h}\right)\end{array}$} & \multirow[t]{3}{*}{$36 \mathrm{~min}$} & $0^{\circ}$ & -2290 & na & na & \multirow{3}{*}{$\begin{array}{l}\text { Schuerger et al., } \\
\text { 2003; 2006; } \\
\text { Fig. } 4 \text { current study }\end{array}$} \\
\hline & & & $\pm 30^{\circ}$ & -1984 & na & na & \\
\hline & & & $\pm 60^{\circ}$ & -1150 & na & na & \\
\hline
\end{tabular}

\footnotetext{
${ }^{\mathrm{c}} L D$ values are defined as the dose equivalents for biocidal factors to directly inactivate $\geq 10^{10}$ viable spores of Bacillus subtilis over given time periods assuming that the biocidal factors are acting in linear manners to inactivate spores without considering latitude or solar zenith angles. The $L D$ values are derived from the literature and from data presented here in Figures 1 to 4 . For example, if spores or B. subtilis were placed on a horizontal surface at the Moon's equator, at local noon, the $L D$ value for UVC + UVB would yield $\geq 10^{-10}$ spores killed in 36 min.
}

Changes were made only to the <LMS.m> MatLab program in the new Supplemental Table S5. All other data remain as published in the original LMS paper (Schuerger et al., 2019). The changed MatLab code in Supplemental Table S5 has been highlighted in yellow.

\section{Discussion}

By increasing the biocidal nature of UV irradiation by 60x in the LMS model, solar UV becomes the dominant biocidal factor on external surfaces on the Moon. The term lethal dose $(L D)$ was defined in the LMS model as a $-10 \log$ reduction in spacecraft bioburden (Schuerger et al., 2019). In practice the first -6 logs in bioburden reductions are empirically derived in the lab, and then the kill rates extrapolated an additional $-4 \operatorname{logs}$. For example, the new $L D$ value in the revised overall LMS model (new Table 2) increased from $23 L D$ s to $248 L D$ s on external surfaces per lunation. Thus, the $L D$ values continue to represent the theoretical (i.e., potential) biocidal dose of a particular factor on any specific surface; the $L D$ term does not imply that such heavy bioburdens are present on spacecraft. It follows that the revised LMS model predicts that external spacecraft surfaces on the Moon will be quickly and thoroughly sterilized during the first lunation after landing. And finally, the original LMS predictions for shallow internal and deep internal surfaces remain unchanged.

\section{References}

Schuerger, A.C., Richards, J.T., Newcombe, D.A., and Venkateswaran, K.J. (2006) Rapid inactivation of seven Bacillus spp. under simulated Mars UV irradiation suggests minimum forward contamination around landing sites. Icarus 181:52-62.

Schuerger, A.C., Smith, D.J., Moores, J.E., and Guenther, R. (2019) A Lunar Microbial Survival (LMS) model for predicting the forward contamination of the Moon. Astrobiology 19:730-756.

Moores, J.E. and Schuerger, A.C. (2020) A cruise-phase microbial survival model for calculating bioburden reductions on past or future spacecraft throughout their missions with application to Europa Clipper. Astrobiology 20:in press; doi.org/10.1089/ast.2019.2205.

Corresponding author: Andrew C. Schuerger Dept. of Plant Pathology University of Florida 505 Odyssey Way Merritt Island, FL 32953

E-mail: schuerg@ufl.edu

Submitted August 18, 2020 